\title{
Energy-Nutrient-Water-Nexus by Microbial Fuel Cell: A Potential Smart Water Solution for Wastewater Treatment Plants
}

\author{
Marcia R. Silva*, Yiming Yang, Kwendo Mwaniki \\ Water Technology Accelerator (WaTA), University of Wisconsin-Milwaukee, Milwaukee, USA \\ Email: *msilva@uwm.edu
}

How to cite this paper: Silva, M.R., Yang, Y.M. and Mwaniki, K. (2022) Energy-Nutrient-Water-Nexus by Microbial Fuel Cell: A Potential Smart Water Solution for Wastewater Treatment Plants. Journal of Sustainable Bioenergy Systems, 12, 12-19. https://doi.org/10.4236/jsbs.2022.121002

Received: January 14, 2022

Accepted: February 28, 2022

Published: March 3, 2022

Copyright $\odot 2022$ by author(s) and Scientific Research Publishing Inc. This work is licensed under the Creative Commons Attribution International License (CC BY 4.0). http://creativecommons.org/licenses/by/4.0/

\begin{abstract}
The Microbial Fuel Cell (MFC) is a bioelectrical system that can convert chemical energy into electrical energy. The anode plays an important role in the improvement of power generation. Zeolite and carbon-based materials were coated in graphene felt anode in this study for proof of concept that the modified material could enhance power generation. Preliminary results showed that the maximum power density with the modified material was $2-2.5$ times higher than the unmodified material using RAS as a substrate and 1.4 times higher using algae as a substrate in our single chamber model, whereas the dual-chamber model displayed a maximum power density of the modified material to be roughly 3 - 4 times higher than in the unmodified microbial fuel cell.
\end{abstract}

\section{Keywords}

Microbial Fuel Cell, Zeolite, Carbon-Based Material, Power Generation

\section{Introduction}

Over two billion people on the planet lack adequate sanitation and one billion do not have sufficient access to potable water. In the US, we use approximately $4 \%$ $5 \%$ of our electricity production for the water infrastructure, and about $1.5 \%$ of electricity goes to wastewater treatment, which is approximately $\$ 45$ billion [1]. But wastewater contains energy, if we could recover the wastewater energy, probably we could make the water infrastructure self-sufficient. Energy recovery from the MFC not only to a sustainable system based on the energy requirement, but also to the production of the next excess energy.

Microbial Fuel Cells (MFC) are bioelectricity systems that can convert the 
chemical energy in the organic sample into electricity by catalytic reaction of microorganisms under anaerobic conditions [2]. Many researchers have investigated the application of MFC in wastewater treatment, including water desalination, chemical production, and direct power generation. They were more focused on understanding microbial activities, reducing electrochemical limitation, and investigating new materials for electrodes [3]-[17].

The mechanism of MFC is well known, as shown in Figure 1. MFC is composed of an anode, cathode, and the Proton-Exchange Membrane (PEM) as the separator. Generating power in MFC depends on the oxidation-reduction (redox) chemical reaction. Wastewater also contains sufficient nutrients for cultivating bacteria. In the anode chamber, the substrate is oxidized under anaerobic conditions by bacteria fermentation which produces protons and electrons. In the cathode chamber, oxygen can be reduced to pure water [4]. Oxygen in the anode chamber will inhibit electricity generation, so the system must be designed to keep the bacteria separated from oxygen. Therefore, adding a Proton Exchange Membrane (PEM) and keeping these two chambers separated are both very inevitable in this situation. PEM not only can keep two chambers' liquid separate, but also can reduce the rate of unwanted substance flux from anode to cathode [1].

However, why MFC is not extensively used at the industry level? The three most significant risks that should be considered about the successful commercialization of MFC are listed next. First is the efficiency rate of power for the wastewater treatment facility. Second, whether MFC can be available at full-scale operations. Third is the cost of materials in MFC [18] [19] [20]. Furthermore, the major

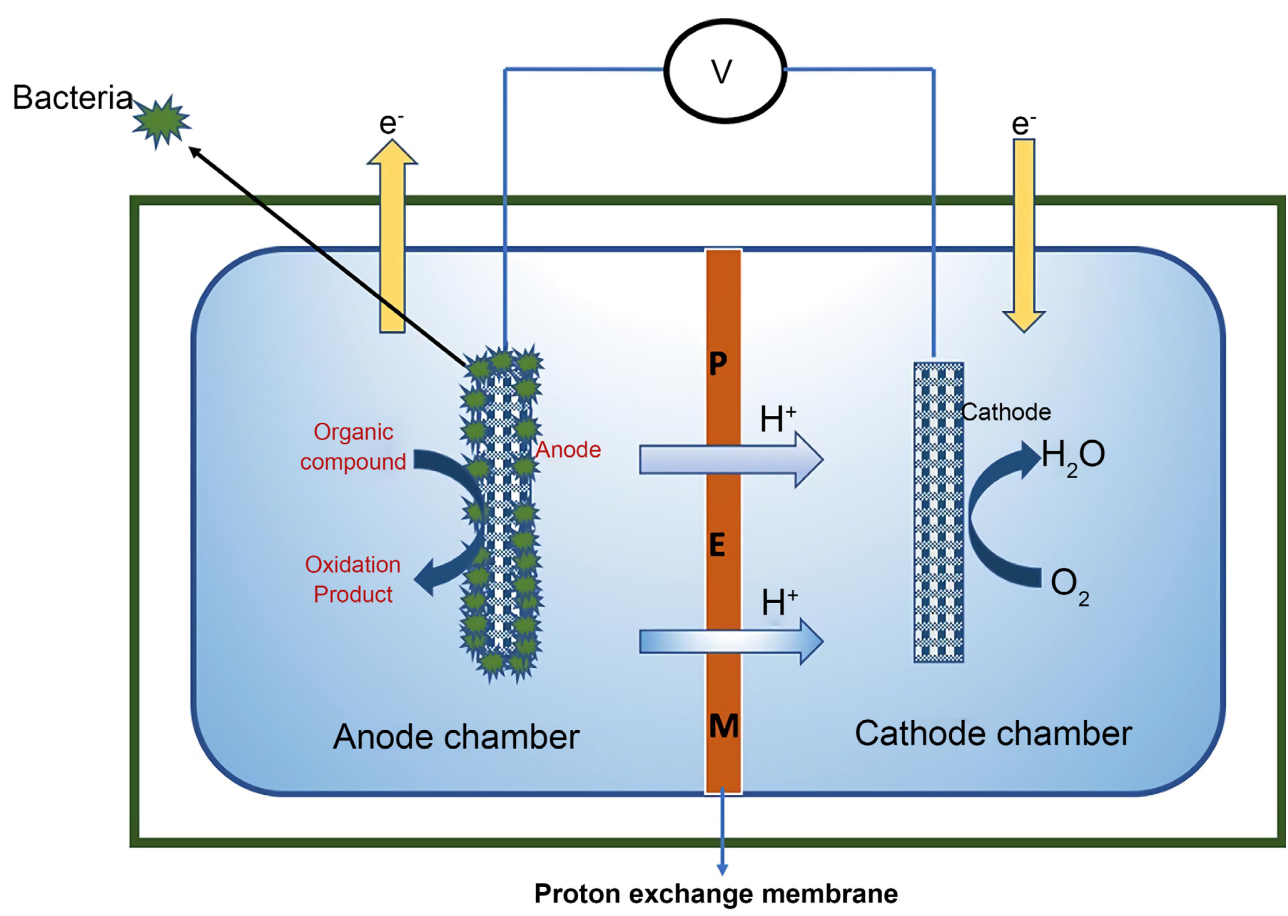

Figure 1. Schematic of basic mechanism in microbial fuel cell. 
limitation of the practical applications in the anode is still not economic, also the character of their property which includes less conductivity, easy corrosion, poor physical property, and environmental compatibility can lead to lower power density, which also limits the application of MFCs in the industrial scale [2] [6]. Therefore, the most important characteristic to consider about the selection of the material for anode would be high electrical conductivity, high surface area, pore diameter, easy to form biofilm and low cost [7].

This study consists of preliminary data for further study of MFC by using zeolite and carbon-based materials, such as Graphene Oxide (GO) to evaluate and improve the performance of the graphite felt anode for obtaining high power density.

\section{Materials and Methods}

The MFC kits, contained with graphite felt anode and cathode were both from the science buddies.com (Figure 2), which area is $0.0063617 \mathrm{~m}^{2}$. The unmodified anode was called the "control anode". The zeolite modified anode was coated with $3.36 \mathrm{~g}$ zeolite soaking in $2.5 \mathrm{mg} / \mathrm{ml} \mathrm{GO}$ solution overnight and incubate in the incubator at $44.5^{\circ} \mathrm{C}$ for 24 hours.

The single chamber MFC consisting of unmodified and modified anode and a bare graphite felt cathode were placed into the cell by separating with Return Activated Sludge (RAS) sample from Milwaukee Metropolitan Sewerage District (MMSD). RAS sample was poured to $1 \mathrm{~cm}$ marker and placed the anode chamber, continuing poring RAS sample to $5 \mathrm{~cm}$ maker and put cathode on top, which should be non-liquid or solid on the top of cathode.

A new model was designed in our lab and made in the machine shop of the School of Freshwater Sciences, following the schematic design in Figure 3, which is a typical dual chambered microbial fuel cell. The model consists of a cathode and anode chamber, separated by a proton exchange membrane (P.E.M.) Two models were used: one with and one without modification.

Modification to the anode was done in a similar manner as in the preliminary experiments. It was performed by taking coated by soaking $3.36 \mathrm{~g}$ of Australian zeolite in a $2.5 \mathrm{mg} / \mathrm{mL}$ graphene oxide solution for 24 hours in the incubator at

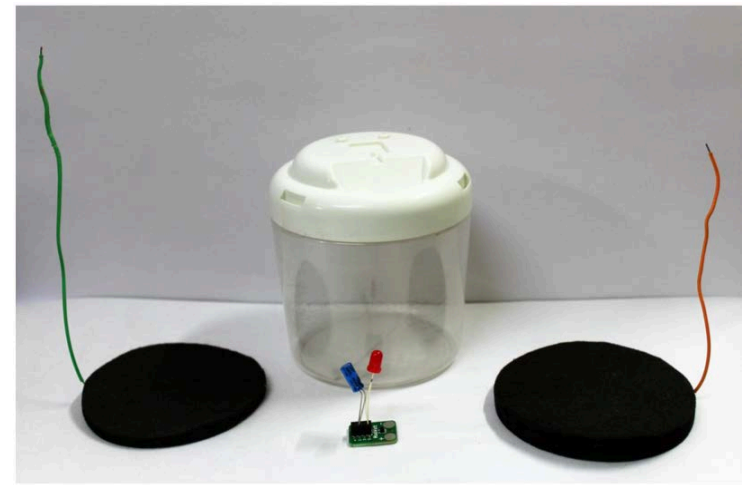

Figure 2. Initial MFC model. 


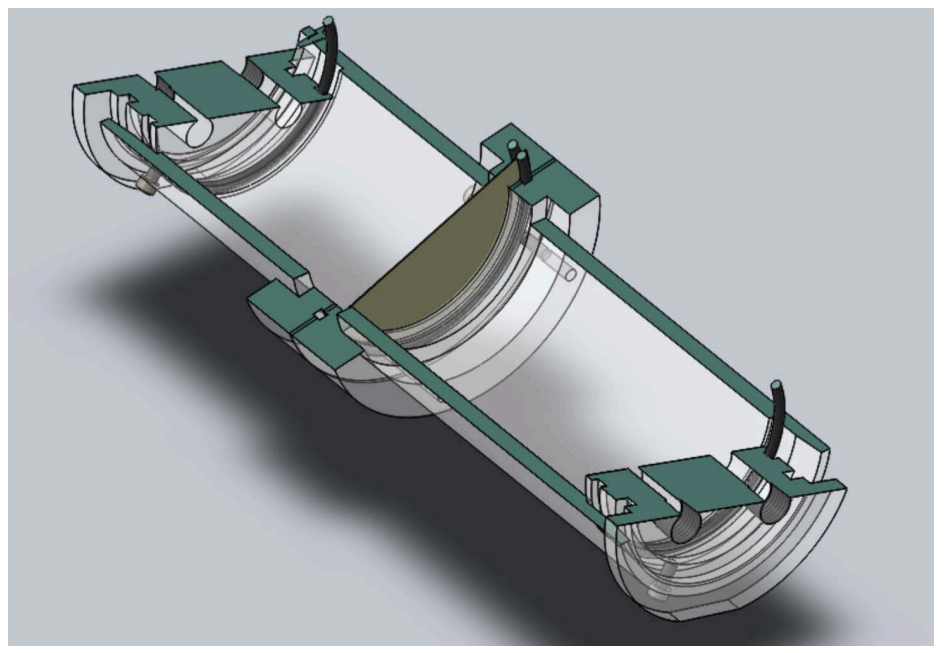

Figure 3. Current MFC chamber model.

$45.5^{\circ} \mathrm{C}$. Each anode chamber was filled with about $200 \mathrm{ml}$ of R.A.S (Returned Activated Sludge).

For both the initial and current model, the fuel cells were connected via an external circuit, to a Titanium wire and connected into Agilent 3458 A 8 1/2 Digit Multi-meter for voltage and current collection.

All data for RAS sample was collected for 6 to 8 days total. Data for algae using the initial model, was collected for 6 to 8 days. The voltages collected in this study were generated every 5 -min interval by using a Multimeter.

The anode and cathode in the MFC were connected to a variable resistance by using a resistance box for polarization curve. Current (I) was obtained from Ohm's Law: $U=I R$, where $U$ is voltage $(V)$, and $R$ is resistance $(\mathrm{Ohm})$. Power $(P)$ was calculated from $\mathrm{P}=\mathrm{U}^{2} / \mathrm{R}$.

\section{Preliminary Results and Discussion}

Figure 4 illustrates that the higher power density was obtained from the zeolite modified anode.

From the power density curve, the maximum power density (with zeolite) in RAS sample was $558 \mu \mathrm{W} / \mathrm{m}^{2}$, which was $2-2.5$ times higher than the one without zeolite which is only $242 \mu \mathrm{W} / \mathrm{m}^{2}$.

Figure 5 shows the polarization curve vs. power density and current density by using algae. For the algae experiment, the power density is $172 \mu \mathrm{W} / \mathrm{m}^{2}$, which is less than RAS sample, but still 1.4 times higher than the control sample (120 $\mu \mathrm{W} / \mathrm{m}^{2}$ ). Which is using the new model, the dual-cell microbial fuel cell has increased the power density and current density significantly; in the order of 130 times higher when compared to the single chamber microbial fuel cell model. It is expected that the dual chamber microbial fuel cell to be better than the single chamber microbial fuel cell because of the proton exchange membrane and the actual are of the anode. Again, readings were taken over a 6 to 8-day period. The modified anode was modulated in the same manner from the older model. The 


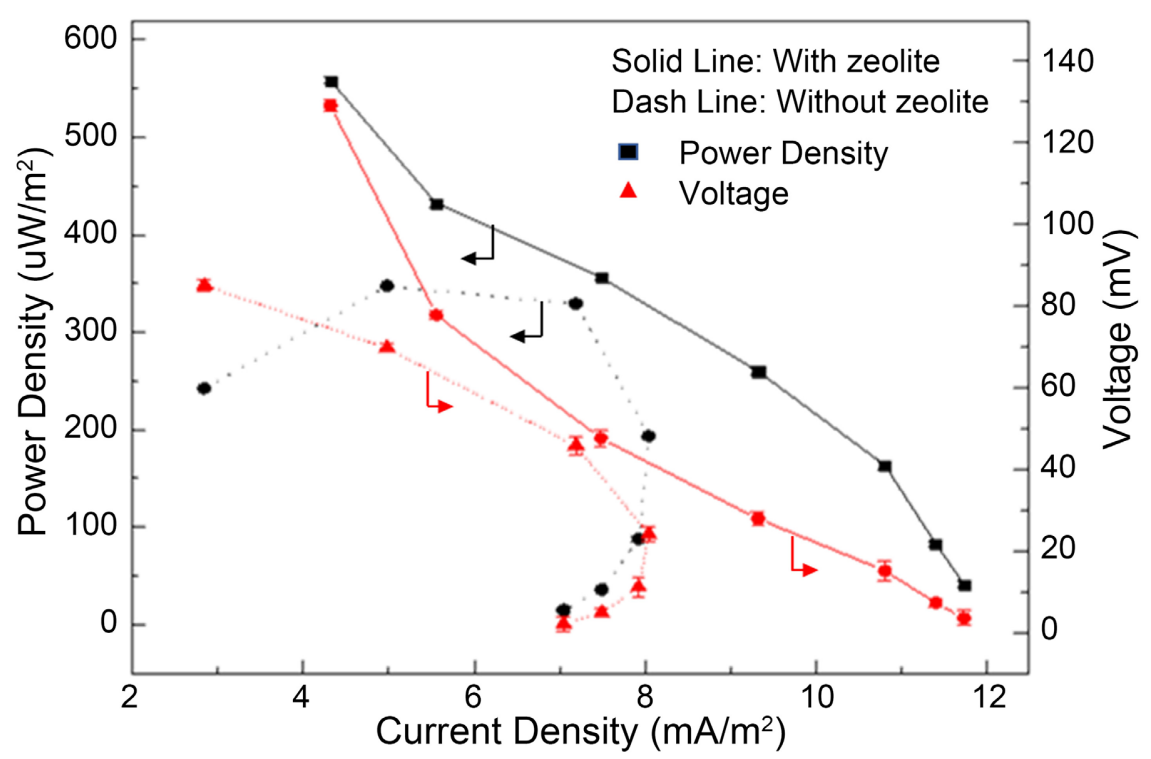

Figure 4. The polarization curves vs. power density and current density by using RAS sample.

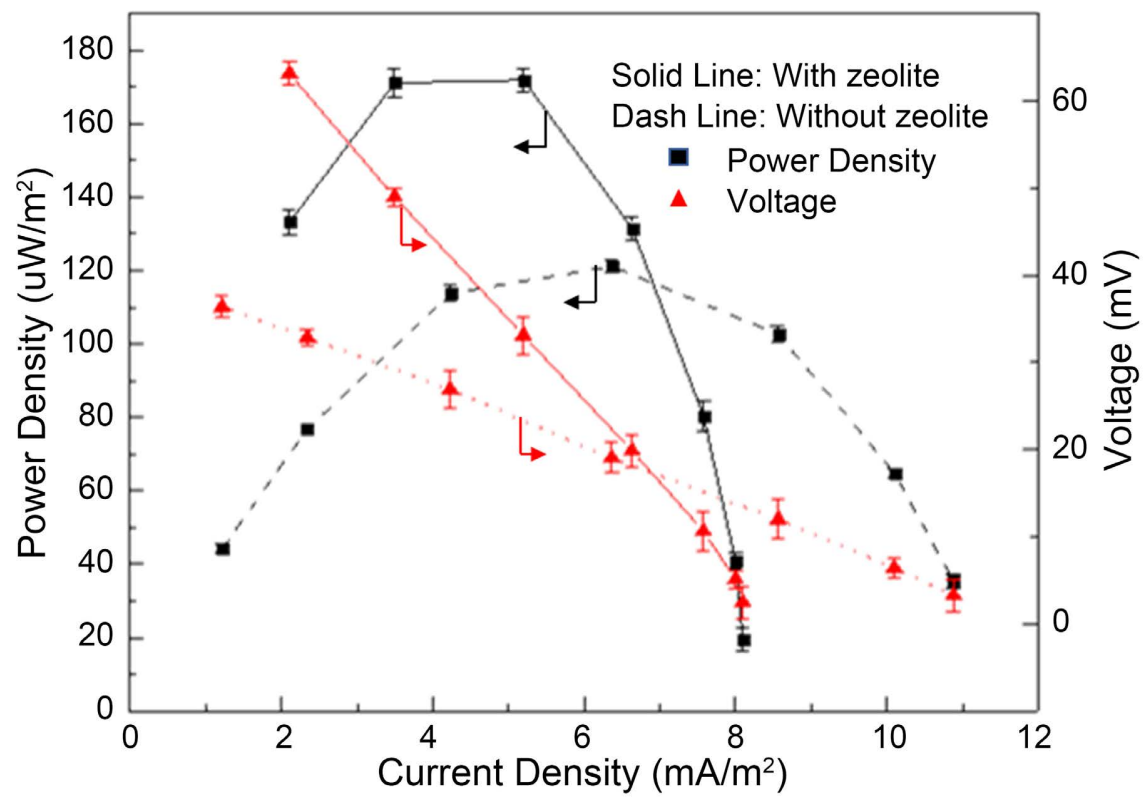

Figure 5. The polarization curve vs. power density and current density by using algae.

preliminary results from the current model show the maximum power density (with zeolite) in RAS sample was $73,747.96 \mu \mathrm{W} / \mathrm{m}^{2}$, which is about $3-4$ times higher than the unmodified material. While both fuel cells display a similar trend, the modified microbial fuel cell exhibits a significantly larger voltage, current density, and power density values as opposed to its counterpart. In terms of voltage, power density and current density, the unmodified fuel cell is three times less than the modified fuel cell.

Selection of coating method and materials used for coating are important to optimize electricity generation. Typically, the anode will perform better if the an- 
ode can have the high surface area and great affinity for bacteria [10]. One study shows that Carbon Nanotubes (CNT) can be a good alternative of material for coating because of its high surface area of volume ratio, high electricity conductivity [11].

Moreover, surface area was found to be more important and crucial in generation of power density [10] [12]. The surface area of cathode makes some effect on the power generation until it up to a certain limit. However, for anode, the larger surface area the greater impact on the generation of energy as the surface increases [11]. In our studies, both zeolite and graphene-based materials increase surface area and anode/bacteria interactions.

Other potential approaches include the use of $0.1 \mathrm{M}$ ferricyanide as the mediator at the cathode can generate higher power generation compared with oxygen [13]. Ferricyanide alone does not guarantee a high-power output, but it does typically increase power output compared to system using dissolved oxygen at the cathode. The distance between anode and cathode should also be a big part to be considering in further study. The maximum power density increased from 720 to $1210 \mathrm{~mW} / \mathrm{m}^{2}$ when the electrode distance was decreased to from $4 \mathrm{~cm}$ to $2 \mathrm{~cm}$ [16]. The increase of power density is because decrease of the internal resistance. However, decreasing the distance even further could lower the power density. When electrode spacing was further reduced to $1 \mathrm{~cm}, \mathrm{P}$ decreased even though a low $\mathrm{R}_{\text {int }}$ of $16 \Omega$. While the maximum power density decreased from 811 to $684 \mathrm{~mW} / \mathrm{m}^{2}$ [17].

Future studies that can potentially make MFC technologies more feasible to adoption of large-scale systems are: 1) conversion of chemical energy of organic and inorganic substrates to electrical energy directly associated with wastewater treatment; and 2) optimization of trade-off of ammonia recovery and energy consumption. Some examples of publications in these fields include one study that showed that a dual chamber MFC was used with a mixed culture of microorganisms which converted substrate to electricity. Also, the initial concentration of $1.5 \mathrm{~g} / \mathrm{L}$ sulfide in wastewater was reduced after day 9 to $0.19 \mathrm{~g} / \mathrm{L}$, and it was removed at day 10 [18]. Another study explored the trade-off of ammonia recovery and energy consumption of Bioeletrochemical Systems (BES) recovering ammonia from wastewater driven by electricity generation [19]. Nitrogen is a key inorganic contaminant in wastewater treatment and a large amount of nitrogen in aquatic ecosystem can result in eutrophication, which is costly (annual cost for removal eutrophication in the United States is about $\$ 2200$ million) [20]. This study indicates the need for further research and optimization of BES systems.

\section{Conclusions}

- Anode modification is an alternative approach to obtain higher power density;

- Increase of surface area of the anode with zeolite coated with graphene oxide enabled higher power density due to increased microbial activity as growth conditions were enhanced; 
- Microbial fuel cell technologies have the potential to become a smart water solution for wastewater treatment plants as it addresses the energy-nutrientwater-nexus. However, more laboratory research and more opportunities for pilot systems deployments are needed.

\section{Acknowledgements}

Authors thank Randy Metzger from the Machine Shop at the UWM School of Freshwater Sciences for making the microbial fuel cell model. This project was funded by UWM Support for Undergraduate Research Fellows (SURF) grant to Yiming Yang and Kwendo Mwaniki.

\section{Conflicts of Interest}

The authors declare no conflicts of interest regarding the publication of this paper.

\section{References}

[1] Logan, B. (2008). Microbial Fuel Cells. Wiley, Hoboken. https://doi.org/10.1002/9780470258590

[2] Logan, B.E. and Regan, J.M. (2006) Microbial Fuel Cells Challenges and Applications. Environmental Science \& Technology, 40, 5172-5180. https://doi.org/10.1021/es0627592

[3] Wu, X., Tong, F., Song, T., et al. (2014) Effect of Zeolite-Coated Anode on the Performance of Microbial Fuel Cell. Journal of Chemical Technology and Biotechnology, 90, 87-92. https://doi.org/10.1002/jctb.4290

[4] Wang, H. and Ren, Z.J. (2013) A Comprehensive Review of Microbial Electrochemical Systems as a Platform Technology. Biotechnology Advances, 31, 1796-1807. https://doi.org/10.1016/j.biotechadv.2013.10.001

[5] Xiao, L., Damien, J., Luo, J., et al. (2012) Crumpled Graphene Particles for Microbial Fuel Cell Electrodes. Journal of Power Source, 208, 187-192. https://doi.org/10.1016/j.jpowsour.2012.02.036

[6] Wrighton, K.C. and Coates, J.D. (2009) Microbial Fuel Cells: Plug-In and Power-On Microbiology. Microbes, 4, 281-287.

[7] Zhang, J., Li, J., Ye, D., Zhu, X., Liao, Q. and Zhang, B. (2014) Tubular Bamboo Charcoal for anode in Microbial Fuel Cells. Journal of Power Source, 272, 277-282. https://doi.org/10.1016/j.jpowsour.2014.08.115

[8] Santoro, C., Arbizzani, C., Erable, B. and Ieropoulos, I. (2017) Microbial Fuel Cells: From Fundamentals to Applications. A Review. Journal of Power Sources, 356, 225-244. https://doi.org/10.1016/j.jpowsour.2017.03.109

[9] Logan, B.E., Hamelers, B., Rozendal, R., Schroder, U., Keller, J., Freguia, S., et al. (2006) Microbial Fuel Cells: Methodology and Technology. Environmental Science \& Technology, 40, 5181-5192. https://doi.org/10.1021/es0605016

[10] Yuan, Y., Zhou, S., Liu, Y. and Tang, J. (2013) Nanostructured Microporous Bio Anode Based on Polyaniline-Modified Natural Loofah Sponge for High-Performance Microbial Fuel Cells. Environmental Science \& Technology, 47, 14525-14532. https://doi.org/10.1021/es404163g

[11] Ren, H., Pyo, S., Lee, J.-I., Park, T.-J., Gittleson, F.S., Leung, F.C.C., et al. (2015) A High- 
Power Density Miniaturized Microbial Fuel Cell Having Carbon Nanotube Anodes. Journal of Power Sources, 273, 823-830. https://doi.org/10.1016/j.jpowsour.2014.09.165

[12] Deval, A., Bhagwat, A. and Dikshit, A. (2014) Significance of Surface Area of Anode in Generation Electricity through Microbial Fuel Cell Fed with Anaerobically Digested Distillery Wastewater. International Journal of Pharma and Bio Sciences, 5, 35-43.

[13] Oh, S.E., Min, B. and Logan, B.E. (2004) Cathode Performance as a Factor in Electricity Generation in Microbial Fuel Cells. Environmental Science \& Technology, 38, 4900-4904. https://doi.org/10.1021/es049422p

[14] Bose, D. and Bose A. (2014) Electrical Power Generation with Himalayan Mud Soil Using Microbial Fuel Cell. Nature Environment and Pollution Technology, 16, 433-439.

[15] Liu, H., Cheng, S. and Logan, B.E. (2005) Power Generation in Fed-Batch Microbial Fuel Cells as a Function of Ionic Strength, Temperature, and Reactor Configuration. Environmental Science \& Technology, 39, 5488-5493. https://doi.org/10.1021/es050316c

[16] Cheng, S., Liu, H. and Logan, B. (2006) Increased Power Generation in a Continuous Flow MFC with Advective Flow through the Porous Anode and Reduced Electrode Spacing. Environmental Science \& Technology, 40, 2426-2432. https://doi.org/10.1021/es051652w

[17] Fraiwan, A. and Choi, S. (2016) A Stackable, Two-Chambered, Paper-Based Microbial Fuel Cell. Biosensors and Bioelectronics, 83, 27-32.

https://doi.org/10.1016/j.bios.2016.04.025

[18] Izadi, P., Rahimnejad, M. and Ghoreyshi, A. (2015) Power Production and Wastewater Treatment Simultaneously by Dual-Chamber Microbial Fuel Cell Technique. Biotechnology and Applied Biochemistry, 62, 483-488. https://doi.org/10.1002/bab.1345

[19] Qin, M., Liu, Y., Luo, S., Qiao, R. and He, Z. (2017) Integrated Experimental and Modeling Evaluation of Energy Consumption for Ammonia Recovery in Bioelectrochemical Systems. Chemical Engineering Journal, 327, 924-931. https://doi.org/10.1016/j.cej.2017.06.182

[20] Dodds, W.K., Bouska, W.W., Eitzmann, J.L., Pilger, T.J., Pitts, K.L., Riley, A.J., Schloesser, J.T. and Thornbrugh, D.J. (2008) Eutrophication of US Freshwaters: Analysis of Potential Economic Damages. Environmental Science \& Technology, 43, 12-19. https://doi.org/10.1021/es801217q 